\title{
RESEARCH ON STATIC PROPERTIES AND STABILITY OF HIGH-RISE TUBULAR 3D PARKING STRUCTURE WITH HOOP STORIES
}

\author{
Yongjun $\mathrm{He}^{1, *}$, Xiaohua Liu ${ }^{1,2}$ and Xuhong Zhou ${ }^{1,3}$ \\ ${ }^{1}$ College of Civil Engineering, Hunan University, Changsha, 410082, PR China \\ ${ }^{2}$ Xi'an Architectural Design-research Institute, Xi'an, 710043, China \\ ${ }^{3}$ Chongqing University, Chongqing 400044, China \\ *(Corresponding author: E-mail: hyj0087@163.com)
}

Received: 23 January 2013; Revised: 28 October 2013; Accepted: 20 December 2013

\begin{abstract}
A new structural arrangement style of high-rise tubular 3D parking structure is presented, which is to set hoop stories like bamboo knots at the proper levels along the height, and the optimal arrangement principle of hoop stories is analyzed. The static properties and stability of the structures with different arrangement schemes of hoop stories are compared. Results indicate that, the lateral stiffness of the structure with hoop stories set according to the equal stability and equal drift principle is remarkably improved; the storey drift becomes more uniform, which benefits the stable operation of hoisting machines; also, the sudden change of the internal forces of columns is relatively moderate and the structural overturning resistance is enhanced. Finally, the parametric analyses on static properties and stability of the structures with optimal arrangement of hoop stories are studied in detail.
\end{abstract}

Keywords: High-rise 3D parking structure, Hoop stories, Optimal arrangement, Static properties, Stability

\section{INTRODUCTION}

The limited urban land resource determines that the simple plane parking in city will inevitably evolve into modern three-dimensional (3D) parking. Among numerous 3D parking structures, the vertical lifting 3D parking structure has become the priority to solve the parking problem in metropolitan area. It fully utilizes limited space to bring the maximum benefits to the customers and strives for more parking spaces by small space. Moreover, it has high speed and low noise, which meets the city environmental protection requirements (Amott [1], Amélie and Bryan [2] and Eduardo et al. [3]).

The high-rise vertical lifting tubular 3D parking structure is very similar to bamboo in its macroscopic structure type, and both are tubular structure with large slenderness ratio. The distinction is that bamboo has bamboo knots with different intervals along its height. However, the existing tubular parking structures have not transverse reinforcing components like bamboo knots. Experiments (Yu and Chung [4], Tommy and Cui [5] and Khosrow [6]) show that natural bamboo has the excellent overall stability and local buckling hardly appears. Additionally, the bending, shearing and compression resistance of bamboo can be improved by $23 \%, 19 \%$, and $7 \%$, respectively, for the existence of bamboo knots. The main reason is that bamboo knots can strengthen the integrity of bamboo, which is beneficial to resisting the shear. On the other hand, bamboo knots are analogous to hinges, which divide 'long rod' into 'short rod' and dramatically decrease the slenderness ratio of bamboo. Therefore, the probability of buckling is effectively reduced. Since bionics was established as a new subject, the structural design in theory and practice has continuously obtained inspiration from biosphere (Ma et al. [7], Karthikeyan et al. [8] and Zhao et al. [9]). The 88-storey twin structure in Malaysia and the wings of large civil aircrafts are both typical examples about the successful practice of bamboo knot bionics in structural design. 
Based on the superior behavior of bamboo, and considering the similarity of the vertical lifting 3D parking structures with bamboo in the aspects of structural type and load feature, a new structural arrangement style of 3D parking structure is presented in this paper, which is to set hoop stories like bamboo knots at its proper levels along the height. Then, the static properties and stability of the structures with different arrangement schemes of hoop stories are compared in detail. Finally, based on parametric analyses, the influences of the bracing stiffness in hoop stories, storey height, and the linear stiffness ratio of beam to column on static properties and stability of the structure with optimal hoop storey arrangement scheme are studied systematically.

\section{ARRANGEMENT SCHEME OF HOOP STORIES OF THE VERTICAL LIFTING TUBULAR 3D PARKING STRUCTURE}

\subsection{Arrangement Principle of Hoop Stories}

The parking function of vertical lifting 3D parking structure makes it be a new structural system different from the ordinary housing structure. Actually, it is a quadrilateral tubular structure consisting of four planar frames along the periphery with few internal horizontal members as shown in Figure 1 (He and Zhou [10]). There are not filled walls and floor slabs. And its storey height is relatively small. All these characters weaken the concept of 'structural storey'. The constraint of beam to column is also weakened, which results in the increase of slenderness ratio of columns. Some columns even can be regarded as long vertical cantilever throughout the structure on extreme condition. Hence, for this kind of tall and slender 3D parking structure, the overall stability may become the governing factor in design like the structural lateral displacement. Therefore, it is important to present a reasonable structural arrangement method to improve the structural behavior and meet its functional requirement.

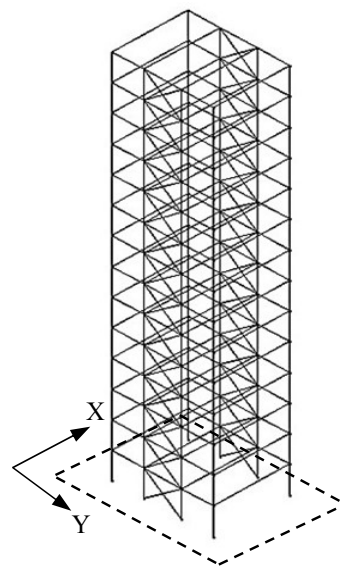

(a)

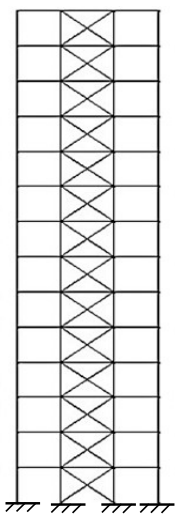

(b)

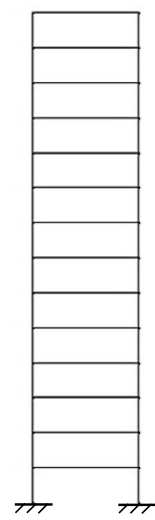

(c)

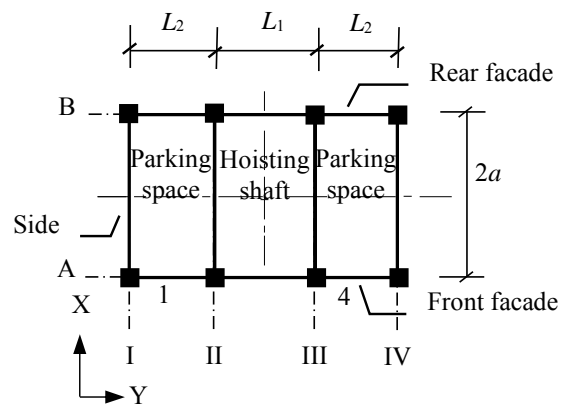

(d)

Figure 1. Conventional Highrise Vertical Lifting Tubular 3D Parking Structure:

(a) Three-dimensional Figure; (b) Front/Rear Frame; (c) Side Frame; (d) Planar Layout

Based on the inspiration from bamboo, the author presents a new structural arrangement style of 3D parking structure, which is to set hoop stories like bamboo knots at its proper levels along the height. As shown in Figure 2, X-shape braces with appropriate stiffness are arranged in the peripheral frames at a specific storey. Also, horizontal X-shape braces are set on the upper and lower parking levels except the hoisting shaft area. Therefore a hoop of the structure is formed, and thus this strengthened storey is named hoop storey. The hoop stories do not occupy inner space of the structure and have no influence on normal hoisting and parking function. 


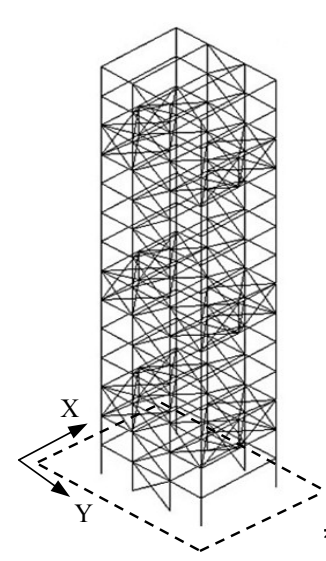

(a)

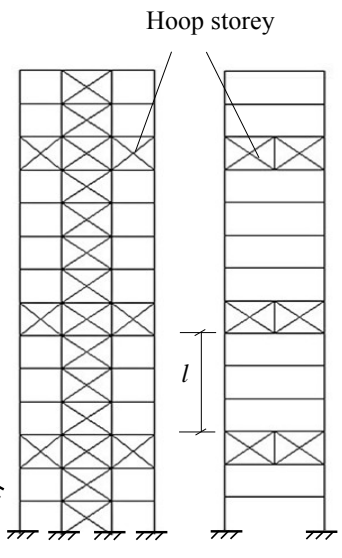

(c)

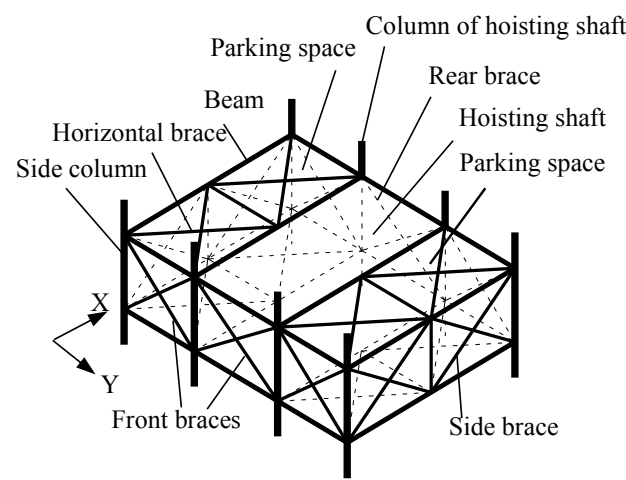

(d)

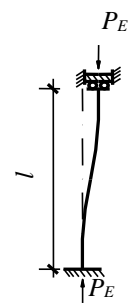

(e)

Figure 2. High-rise Vertical Lifting Tubular 3D Parking Structure with Hoop Stories:

(a) Three-dimensional Figure; (b) Front/rear Frame; (c) Side Frame; (d) Schematic Diagram of a Hoop Storey; (e) Model of an Equivalent Short Column between Two Adjacent Hoop Stories

Obviously, the hoop stories in the tubular 3D parking structure essentially differ from the horizontal strengthened stories in traditional high-rise structure in the structural arrangement style and mechanism. The formation of traditional strengthened stories is usually setting horizontal outriggers with large stiffness between the inner tube and outer frame using the equipment, refuge or transfer stories. These outriggers will make the inner and outer tubes work cooperatively, and cause the redistribution of internal forces as well as the improvement of lateral stiffness finally. Generally, the arrangement of strengthened stories follows the principle of minimizing the top lateral displacement. However, the optimal layout of hoop stories in the tubular 3D parking is based on the equal stability and equal drift principle. That is, the stabilities of various columns between any two adjacent hoop stories are identical and the drifts between any two adjacent hoop stories are also identical. The purpose is to reduce the lateral displacement and improve overall stability simultaneously by strengthening the structural integrity and reducing the slenderness ratios of columns.

The mechanism as well as determination of the optimal arrangement intervals of hoop stories in the high-rise tubular 3D parking structure can be interpreted as follows. For convenience, the side planar frame in the structure as shown in Figure 2(c) is taken as the analytical model. Since the equivalent linear stiffness of hoop storey is greatly larger than that of a column, the hoop stories can be regarded as rigid beam, which completely constrains the rotation of ends of the columns connected with the hoop stories. Also, compared with columns, the linear stiffness of beams in the common stories is so small that their restraint to columns can be ignored. Considering the lateral displacement of the frame, columns between two adjacent hoop stories can be approximately regarded as strut that the lower end is fixed and the upper one can shift but not rotate. Economical and rational design for framework should ensure that all columns buckle simultaneously (Li [11]). Actually, the overall stability of framework has equivalence relationship with the stability of any column between two adjacent hoop stories in the framework on this condition. Therefore, the overall stability analysis of the structure can eventually be transformed into stability analysis of the equivalent short columns between two adjacent hoop stories.

Under vertical loads, the axial force of various columns in the $i$-th storey of the structure can be calculated as 
$N_{i}=\sum_{j=i+1}^{n} \mathrm{G}_{j} / m_{i}$

where, $\sum_{j=i+1}^{n} \mathrm{G}_{j}$ is the sum of vertical gravitational loads above the $i$-th storey, including the self weight of structural components and vehicle loads; $m_{i}$ is the number of columns in the $i$-th storey; and $n$ is the number of stories.

The Euler critical load of one equivalent short column between two adjacent hoop stories as shown in Figures 2(c) and (e) can be expressed as

$$
P_{E}=\pi^{2} E I_{e} /(\eta l)^{2}
$$

in which, $I_{e}, l$, and $\eta$ are the cross sectional moment of inertia, length, and calculated length coefficient of the equivalent short column, respectively. The length of the equivalent short column is the net height between two adjacent hoop stories (excluding the hoop stories) as shown in Figure 2(c). Also, since the columns between two adjacent hoop stories can be approximately regarded as strut that the lower end is fixed and the upper one can shift but not rotate as mentioned above, and the calculated length coefficient of this kind of strut as shown Figure 2(e) is apparently 1.0, so here $\eta=1.0$.

Based on the equivalent axial forces on the tops of various equivalent short columns, various hoop-storey intervals, namely the lengths of equivalent short columns, are adjusted according to the equal stability principle, that is, all the equivalent short columns buckle simultaneously. The preliminary arrangement scheme of hoop stories can be obtained by tentative calculation.

To ensure various members be stressed as uniformly as possible, the optimal arrangement scheme of hoop stories should be selected from the preliminary ones according to the equal drift principle, that is, the drifts of any two adjacent hoop stories should be as identical as possible. Since various hoop stories are regarded as rigid beams and have no bending deformation, the drift of two adjacent hoop stories $\Delta_{i}$ completely comes from the deformation of columns for the horizontal loads applied on various stories. According to structural mechanics, $\Delta_{i}$ can be calculated as

$$
\Delta_{i}=l^{3} V_{i} / 12 E I_{i}
$$

where, $V_{i}=\sum_{j=i}^{n} F_{j}$ is the sum of the horizontal loads above the hoop storey; $I_{i}=\sum_{1}^{m} I_{e}$ is the sum of the cross sectional moments of inertia of various equivalent short columns.

As above mentioned, the axial force and the Euler critical load of one equivalent short column can be obtained from Eqs. 1 and 2, respectively, and the drifts of equivalent short columns can be calculated by Eq. 3. Then we can adjust the intervals of the two adjacent hoop stories, namely, the lengths of the equivalent short columns, to meet the equal stability and equal drift requirement and get the optimal arrangement of hoop stories. However, it is difficult to find a scheme that can meet the equal stability and equal drift requirement at the same time due to the indivisibility of the number of stories. Therefore, we can just adjust the intervals of hoop stories to minimize the difference between the axial force and the Euler critical load, as well as that of their drifts as 
possible. And a set of intervals most close to the accurate solution can be obtained. Based on this method, a Matlab program is developed in this paper to iterate and calculate the optimal arrangement scheme of hoop stories. And for the tubular 3D parking structures with different numbers of stories commonly used in practical engineering, the optimal intervals of hoop stories from bottom to top of the structures are obtained as shown in Table 1.

Table 1. The Optimal Arrangement Schemes of Hoop Stories of the Structures with Different Numbers of Stories

\begin{tabular}{ccccccccccc}
\hline Total number of stories & 11 & 12 & 13 & 14 & 15 & 16 & 17 & 18 & 19 & 20 \\
\hline Intervals of hoop stories & $1,2,3$ & $1,2,3$ & $2,3,4$ & $2,3,4$ & $2,3,5$ & $2,3,5$ & $3,4,5$ & $3,4,5$ & $3,4,6$ & $3,5,7$ \\
\hline
\end{tabular}

\subsection{Comparison on Static Properties of the Structures with Different Arrangements of Hoop Stories}

\subsubsection{Analytical models}

Taking the 14-storey structures as examples, the static properties of the 3D parking structures with different arrangement schemes of hoop stories such as K000, K234, K135, and K333, respectively, are compared. The intervals of hoop stories of various schemes are described in Table 2. The K234 is the optimal arrangement scheme as described in Table 1.

Table 2. Different Arrangement Schemes of Hoop Stories of the 14-storey Structures

\begin{tabular}{ccccc}
\hline Arrangement scheme & K000 & K234 & K135 & K333 \\
\hline Intervals of hoop stories & $\begin{array}{c}\text { Without hoop stories } \\
\text { stories }\end{array}$ & $2,3,4$ & $1,3,5$ & $3,3,3$ \\
\hline
\end{tabular}

The span along $\mathrm{X}$ direction of the structure is $6.0 \mathrm{~m}$ and those of various bays along $\mathrm{Y}$ direction are $2.5,3.0$, and $2.5 \mathrm{~m}$, respectively. The storey height is taken as $2.2 \mathrm{~m}$. Additionally, the components are assumed to be made of Q235 steel (Yield Strength $235 \mathrm{MPa}$ ), and the modulus of elasticity of steel is $2.1 \times 10^{5} \mathrm{~N} / \mathrm{m}^{2}$. The columns and beams are made of H-shaped sections H-250 $\times 300 \times 8 \times 10$ (in which, 250,300, 8, and 10 are the height of the cross section, width of the flange, thickness of the web, and the thickness of the flange, respectively; the unit is $\mathrm{mm}$; and similarly hereinafter) and $\mathrm{H}-100 \times 100 \times 6 \times 8$, respectively. The strong axis of the H-section columns is parallel to the longitudinal direction(Y-axis) of the building. And the braces are circular steel tube $\phi 152 \times 5$. The horizontal concentrated loads of each $1 \mathrm{kN}$ are applied on nodes of the front facade of the structure to proximately simulate wind load. Meanwhile, the vertical concentrated loads of each $8 \mathrm{kN}$ are exerted on column nodes of the structure to denote the vehicle load and self weight of the structure, hoisting machines and other affiliated equipments (Hyo and Jong [12]).

Finite element models of the structures are established by APDL language based on ANSYS software. All the beams and columns are simulated by BEAM188 element, while the braces are simulated by LINK8 element (Salemi et al. [13]). The influence of geometric nonlinearity is taken into consideration in the analysis of this kind of tall and slender structures.

\subsubsection{Lateral displacement and storey drift}

The lateral displacement and storey drift (along the transversal direction) curves of various models are displayed in Figures 3 and 4, respectively. It can be seen from Figure 3 that the lateral displacements of the structures with hoop stories are only about $1 / 5$ of that of the structure without hoop stories. This indicates that the effect of hoop stories on confining the structural lateral 
displacement is remarkable. Additionally, the top lateral displacement of the model K234 with hoop stories arranged according to the equal stability and equal drift principle decreases by the greatest degree and the sudden change of the lateral displacement along the structural height is not notable. Although the lateral displacements of models K333 and K135 are also reduced effectively for the arrangement of hoop stories, but there exists sudden change at the lower and upper parts of the structures, respectively. It can be further seen from Figure 4 that, the storey drifts of the structures with hoop stories fluctuate within small range and the fluctuation amplitudes are greatly less than that of the structure without hoop stories. Also, the fluctuation amplitude of storey drift of the model K234 basically keeps constant and is less than those of the models K333 and K135. This is in conformity with the equal lateral displacement principle and beneficial to the stable operation of hosting machine in the vertical lifting 3D parking structure.

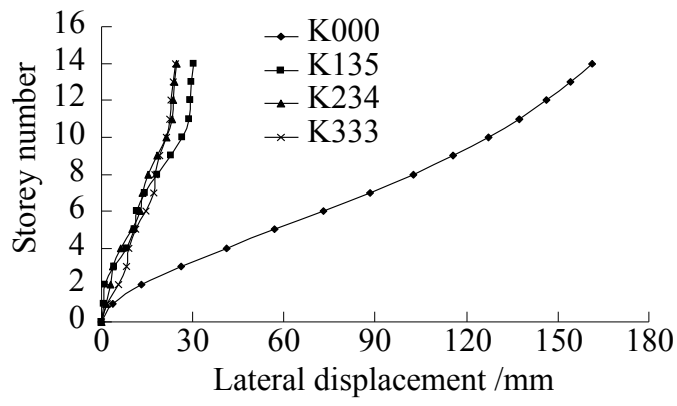

Figure 3. Lateral Displacements of the Structures with Different Arrangement Schemes of Hoop Stories

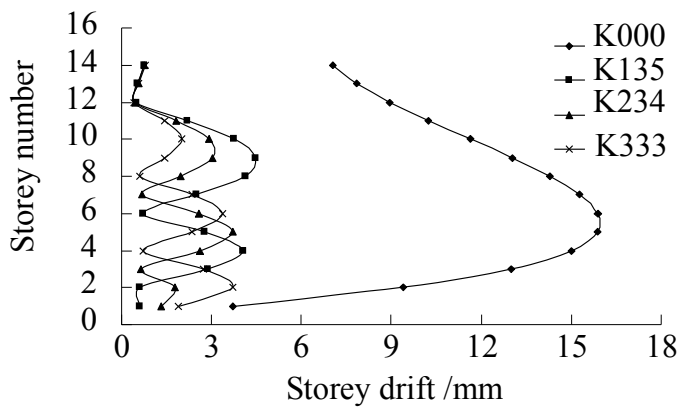

Figure 4. Storey Drifts of the Structures with Different Arrangement Schemes of Hoop Stories

\subsubsection{Internal force distribution of columns}

The columns with largest internal forces on the leeward side are taken to analyze. The influence law of hoop stories on distribution of internal forces is studied, and the mechanism of decrease in structural lateral displacement is accordingly investigated. The variation curves of axial force, shear force and bending moment of columns of various structures along the structural height are displayed in Figures 5, 6, and 7, respectively. From the figures, some information can be obtained as follows.

1) The axial force of columns in the scheme K000 almost linearly decreases along the structural height, while sudden change in those of the structures with hoop stories appears near the hoop stories. Also, in comparison with the scheme K000, the axial forces of columns of the schemes K135, K234 and K333 increase by almost 12\%, 15\%, and 19\%, respectively. Actually, the hoop stories can be regarded as rigid beams between the columns, which powerfully strengthen the relation of the columns. The shear force can thus be transformed into axial force of columns sufficiently when horizontal load is applied on the structure. This will result in increase of the axial force of columns. Further, the increased axial force of columns effectively forms into the torque of couple, which can resist the overturning moment caused by the horizontal load. Thus, the lateral displacement can be remarkably reduced and the structural overturning resistance is improved accordingly. 


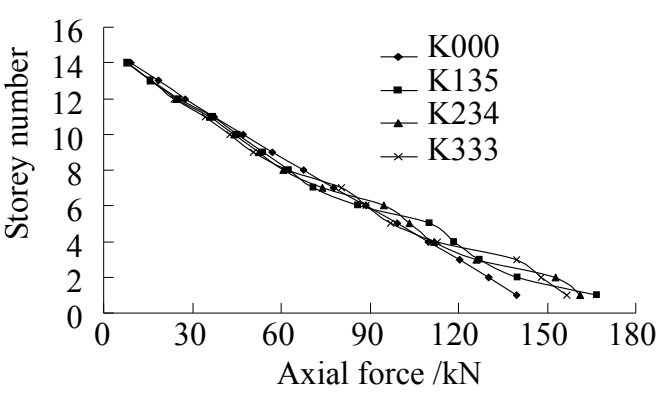

Figure 5. Axial Forces of Columns of the Structures with Different Arrangement Schemes of Hoop Stories

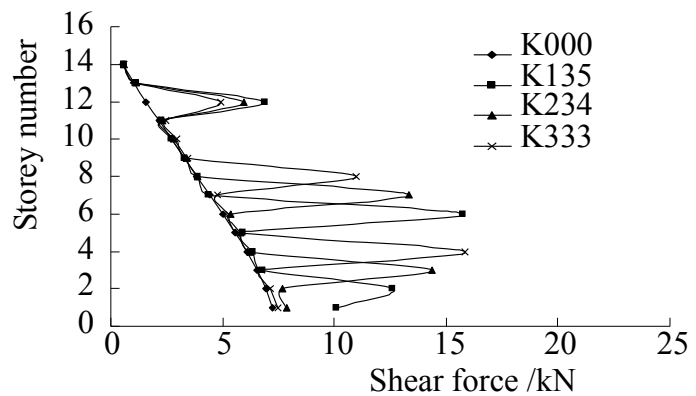

Figure 6. Shear Forces of Columns of the Structures with Different Arrangement Schemes of Hoop Stories

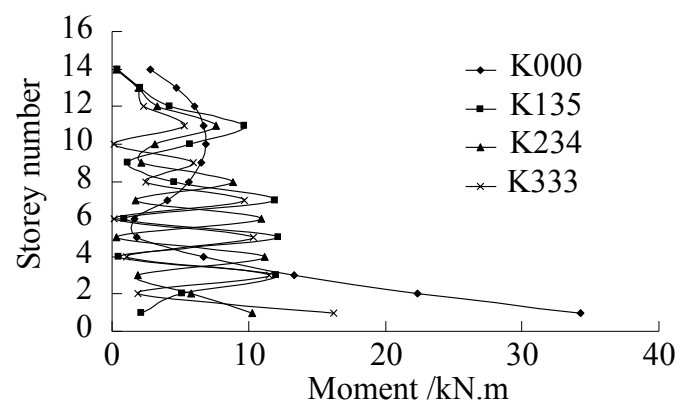

Figure 7. Bending Moments of Columns of the Structures with Different Arrangement Schemes of Hoop Stories

2) Sudden increase in shear forces of columns occurs at hoop stories, but change of those at the adjacent stories of hoop stories is not notable. The reason is that, the structural lateral displacement is continuous along the height but there exists sudden increase in shear stiffness of the columns in the hoop stories for the arrangement of cross braces, which results in the shear force concentration of columns in these stories. The strengthening measure of shear resistance should be considered at the column ends connected to the hoop stories. Additionally, the sudden change in shear force of the scheme K234 is minimum, which indicates that the rational arrangement of hoop stories is of benefit to moderating the sudden change of shear force.

3) The bending moment of bottom columns of scheme K000 is greatly larger than those of the schemes with hoop stories. Particularly, the bending moment of columns of the scheme K234 fluctuates along the height within the smallest range. Conclusions can be drawn that the hoop stories set with reasonable intervals in the structure will weaken the moment concentration at the bottom of the structure and make the distribution of moment be more uniform. The main reason is that, the arrangement of hoop stories leads to the increase in axial force of the columns, which partly provides the overturn-resisting moment and effectively reduces the bending moment of columns. On the other hand, since the structural lateral displacement decreases for the existence of hoop stories, the additional moment caused by second-order effect also decreases consequently. 


\subsection{Comparison in Stability of the Structures with Different Arrangement Schemes of Hoop Stories}

\subsubsection{Linear buckling analysis}

Although linear buckling analysis cannot accurately obtain the ultimate bearing capacity, it can preliminarily reflects the structural overall stability and the calculation process is simple. Additionally, linear buckling mode is usually adopted as the initial imperfection distribution pattern in the imperfection sensitivity analysis (Zhao et al. [14]). Therefore, it is necessary to do linear buckling analysis before the nonlinear buckling analysis. As the key points of research, the structural first order buckling load and mode are discussed in this section. The values of various parameters are identical with those in Section 2.2.1. The first-order linear buckling loads of the structures with different arrangement schemes of hoop stories are summarized in Table 3.

Table 3. Linear Buckling Loads of the Structures with Different Arrangement Schemes of Hoop Stories

\begin{tabular}{ccccc}
\hline Arrangement scheme & K000 & K135 & K234 & K333 \\
\hline Buckling load $/ \mathrm{kN}$ & 89.7 & 317.4 & 390.3 & 351.5 \\
\hline
\end{tabular}

It can be seen from Table 3 that the buckling loads of the structures with hoop stories are markedly larger than that of the structure without hoop stories, which indicates that the hoop stories can notably improve the structural overall stability as expected. Moreover, the eminent behavior of the model K234 with optimal arrangement of hoop stories shows the importance of rational arrangement intervals of hoop stories by equal stability and equal drift principle.

The first order bucking modes of the structures with four different arrangement schemes of hoop stories are displayed in Figure 8. Obviously, the bucking mode of the model K000 presents inclination as a whole towards the transverse (X) direction, so the governing direction is transversal on the linear buckling of the building. For the model K234, there exists remarkable drift between the first and second hoop stories along the transverse direction, which leads to the structural overall buckling. The storey drifts at the upper and lower parts of the structure is not remarkable. Similarly, the overall buckling of the models K135 and K333 is also caused by the excessive storey drifts between two adjacent hoop stories at different parts of the structures. Therefore, the hoop stories have strong restriction effect on the columns. Actually, this kind of high-rise tubular structure can be regarded as a vertical cantilever fixed to the ground, and the whole structure is divided into several short columns for the existence of the hoop stories. And the structural overall stability depends on the stability of equivalent short columns between adjacent hoop stories. This results in remarkable increase of the structural overall stability bearing capacity.

\subsubsection{Nonlinear stability analysis}

Linear buckling analysis cannot reflect the influence of initial imperfection and usually overestimates the structural stability bearing capacity. Therefore, it is necessary to do structural nonlinear stability analysis. In this paper, an incremental-iterative method based on the Newton-Raphson method combined with constant arc length is adopted to do nonlinear stability analysis by tracking the equilibrium path (Widjaja [15]). The values of various parameters and load pattern are identical with those in Section 2.2.1. For this kind of tall and slender structure, only the geometric nonlinearity is taken into consideration. The influence of geometric imperfection is also considered and the imperfection amplitude of $30 \mathrm{~mm}$ (about 1/1000 of the structural height) is 
preliminarily adopted. Here, the first order linear buckling mode is adopted as the geometric imperfection distribution pattern, and the geometric imperfection is along the transversal direction of the structure. The load-displacement curves are displayed in Figure 9, in which, the load is the vertical concentrated load exerted on each column node, and the displacement is the lateral displacement of the top of the structure along the transverse direction. In the process of the structural displacement increasing with increase of the load exerted on the structure, if a little increase of load results in rapid increase of structural displacement and the structure is about to fail, the load at this moment is defined as the structural ultimate load in this paper. Evidently, the ultimate load implies the structural stability bearing capacity.

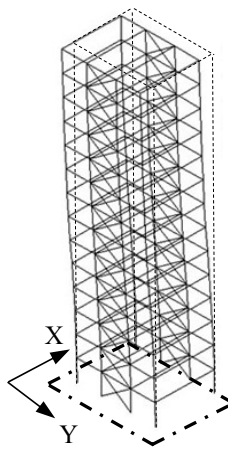

(a)

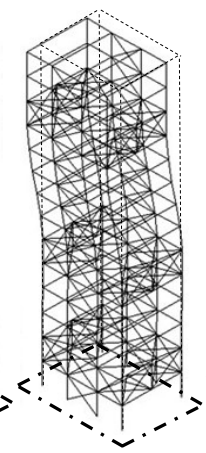

(b)

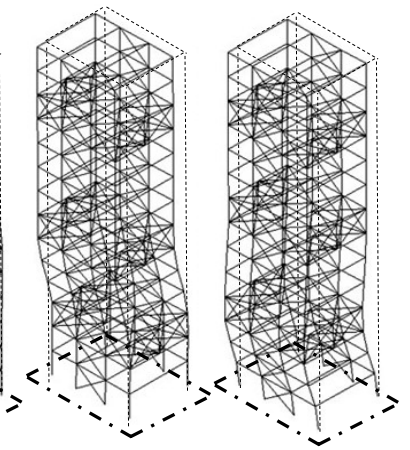

(c) (d)

Figure 8. Buckling Modes of the Structures with Different Arrangement Schemes of Loop Stories: (a) K000; (b) K135; (c) K234; (d) K333

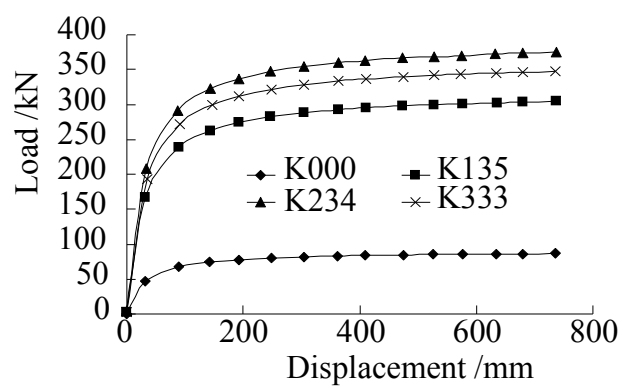

Figure 9. Load-displacement Curves of the Structures with Different Arrangement Schemes of Loop Stories

It can be seen that the stability bearing capacity of model K234 is obviously larger than those of the others. This is consistent with the result of linear buckling analysis and further demonstrates the superiority of hoop stories set according to the equal stability and equal drift principle. Additionally, as shown in Figure 9 and Table 3, the nonlinear stability bearing capacity is remarkably less than the linear result, so the geometrically nonlinear effect cannot be ignored in stability analysis of this kind of structure.

\section{PARAMETRIC ANALYSIS OF STATIC PROPERTIES}

In Section 2, the static property and stability of the high-rise tubular 3D parking structures with different arrangement schemes of hoop stories are compared in detail. And the rationality of the optimal arrangement principle of hoop stories is thus verified. To further obtain the reasonable design values of various parameters of the structure with optimal arrangement of hoop stories, the influence of the parameters on structural static properties, including the maximum lateral displacement, story drift angle, and peak stress, are investigated, respectively. The 14-storey 3D parking structure with optimal arrangement scheme of hoop stories, namely the model K234 as described in Table 1, is taken to analyze. And the geometrical nonlinearity is considered.

\subsection{Influence of the Cross Section of the Side Braces}

Let the cross section of front/rear braces be $\phi 121 \times 4$, and different cross sections of the side braces such as $\phi 73 \times 3, \phi 89 \times 4, \phi 102 \times 4, \phi 121 \times 4, \phi 152 \times 5, \phi 168 \times 8$, as well as $\phi 203 \times 9$ are considered, respectively. The other parameters and loads are identical with those described in Section 2.2.1. The static analytical results are summarized in Table 4 . It can be seen that the maximum lateral 
displacement, story drift angle (along the transversal direction, and similarly hereinafter) and peak stress notably decrease with increase of the cross section of the side braces within a certain range. However, the further increase of the cross section almost has no remarkable effect on drop of these static indices when it reaches to a certain value. Therefore, there exists a rational upper limit for the cross section of side braces, and a hoop storey can be approximately regarded as a rigid beam in this limit case. For the model in this section, the cross section of the side braces in the hoop stories should not exceed $\phi 152 \times 5$, and the further increase after this value is not economical.

Table 4. Static indices of the structures with different cross sections of side braces

\begin{tabular}{|c|c|c|c|c|c|c|c|}
\hline \multicolumn{2}{|c|}{ Side braces } & \multirow{2}{*}{$\begin{array}{c}\text { Maximum } \\
\text { lateral } \\
\text { displacement } \\
\text { (Transversal) } \\
\text { /mm }\end{array}$} & \multirow[b]{2}{*}{$\begin{array}{c}\text { Decline rate } \\
\text { of maximum } \\
\text { lateral } \\
\text { displacement }\end{array}$} & \multirow{2}{*}{$\begin{array}{c}\text { Maximum } \\
\text { storey drift } \\
\text { angle } \\
\text { (Transversal) } \\
/ \times 10^{-3} \mathrm{rad}\end{array}$} & \multirow[b]{2}{*}{$\begin{array}{l}\text { Decline rate } \\
\text { of maximum } \\
\text { storey drift } \\
\text { angle }\end{array}$} & \multirow[b]{2}{*}{$\begin{array}{l}\text { Peak stress } \\
\quad / \mathrm{MPa}\end{array}$} & \multirow[b]{2}{*}{$\begin{array}{l}\text { Decline rate } \\
\text { of peak stress }\end{array}$} \\
\hline $\begin{array}{c}\text { Cross } \\
\text { section }\end{array}$ & $\begin{array}{c}\text { Cross- } \\
\text { sectional } \\
\text { area } / \mathrm{mm}^{2}\end{array}$ & & & & & & \\
\hline$\phi 73 \times 3$ & 337 & 36.3 & $79.4 \%$ & 2.21 & $71.7 \%$ & 39.14 & $39.9 \%$ \\
\hline$\phi 89 \times 4$ & 546 & 30.8 & $82.5 \%$ & 1.92 & $75.4 \%$ & 37.43 & $42.5 \%$ \\
\hline$\phi 102 \times 4$ & 628 & 29.5 & $83.3 \%$ & 1.85 & $76.3 \%$ & 37.02 & $43.1 \%$ \\
\hline$\phi 121 \times 4$ & 747 & 28.1 & $84.1 \%$ & 1.78 & $77.2 \%$ & 36.57 & $43.8 \%$ \\
\hline$\phi 152 \times 5$ & 1174 & 25.2 & $85.7 \%$ & 1.62 & $79.2 \%$ & 35.61 & $45.2 \%$ \\
\hline$\phi 168 \times 8$ & 2060 & 22.9 & $87.0 \%$ & 1.49 & $80.9 \%$ & 34.82 & $46.5 \%$ \\
\hline$\phi 203 \times 9$ & 2805 & 22.0 & $87.5 \%$ & 1.33 & $95.5 \%$ & 34.47 & $47.1 \%$ \\
\hline \multicolumn{2}{|c|}{ Without side braces } & 176.1 & - & 7.81 & - & 65.04 & - \\
\hline
\end{tabular}

PS: The decline rate of maximum lateral displacement is the percentage decrease of the maximum lateral displacement of the structure with side braces in comparison with that of the structure without side braces; similarly, those of the maximum story drift angle and peak stress are defined, the same as the following tables.

\subsection{Influence of the Cross Section of the front/Rear Braces}

Assume that the cross section of side braces is $\phi 152 \times 5$, and different cross sections of the front/rear braces such as $\phi 73 \times 3, \phi 102 \times 4, \phi 121 \times 4, \phi 152 \times 5, \phi 168 \times 8$, as well as $\phi 203 \times 9$ are considered, respectively. The horizontal concentrated loads of each $5 \mathrm{kN}$ are applied on the nodes in one side frame of the structure along the longitudinal direction, and the vertical concentrated loads of each $8 \mathrm{kN}$ are exerted on various column nodes. The other parameters are identical with those in Section 2.2.1. The results by static analysis are listed in Table 5.

The results show that the setting of the front/rear braces of the hoop stories can significantly improve the lateral stiffness along the longitudinal direction and reduce the values of various static indices. Also, when the cross section of the front/rear braces reaches a certain value, its further increase just brings about slight decrease of the structural maximum lateral displacement, storey drift angle, and the peak stress. Additionally, synthesizing the results in Tables 4 and 5 shows that, the structural transverse stiffness is comparatively less than the longitudinal one, and thus the structural deformation depends on the transverse lateral displacement. 
Table. 5 Static Indices of the Structures with Different Cross Sections of Front/Rear Braces

\begin{tabular}{ccccccc}
$\begin{array}{c}\text { Cross section of } \\
\text { the front/rear } \\
\text { braces }\end{array}$ & $\begin{array}{c}\text { Maximum } \\
\text { displacement } \\
/ \mathrm{mm}\end{array}$ & $\begin{array}{c}\text { Decline rate of } \\
\text { maximum } \\
\text { displacement }\end{array}$ & $\begin{array}{c}\text { Maximum } \\
\text { storey drift } \\
\text { angle } / \times 10^{-3} \mathrm{rad}\end{array}$ & $\begin{array}{c}\text { Decline rate of } \\
\text { maximum storey } \\
\text { drift angle }\end{array}$ & $\begin{array}{c}\text { Peak stress } \\
/ \mathrm{MPa}\end{array}$ & $\begin{array}{c}\text { Decline rate of } \\
\text { peak stress }\end{array}$ \\
\hline$\phi 73 \times 3$ & 25.2 & $85.2 \%$ & 1.57 & $82.3 \%$ & 49.64 & $57.4 \%$ \\
$\phi 89 \times 4$ & 19.6 & $88.5 \%$ & 1.16 & $87.0 \%$ & 44.81 & $61.6 \%$ \\
$\phi 102 \times 4$ & 18.3 & $89.3 \%$ & 1.06 & $88.1 \%$ & 43.52 & $62.7 \%$ \\
$\phi 121 \times 4$ & 16.8 & $90.1 \%$ & 0.94 & $89.4 \%$ & 41.98 & $64.0 \%$ \\
$\phi 152 \times 5$ & 13.7 & $92.0 \%$ & 0.70 & $92.1 \%$ & 38.38 & $67.1 \%$ \\
$\phi 168 \times 8$ & 10.9 & $93.5 \%$ & 0.58 & $93.5 \%$ & 34.7 & $70.2 \%$ \\
$\phi 203 \times 9$ & 9.8 & $94.2 \%$ & 0.53 & $94.1 \%$ & 33.44 & $71.3 \%$ \\
$\begin{array}{c}\text { Without } \\
\text { front/rear braces }\end{array}$ & 170.3 & - & 8.90 & - & 116.58 & - \\
\hline
\end{tabular}

\subsection{Influence of Storey Height}

The storey height of parking structures usually varies from 1.7 to $2.2 \mathrm{~m}$. Here let the cross sections of the front/rear and side braces be $\phi 121 \times 4$ and $\phi 152 \times 5$, respectively. The other parameters and loads are identical with those in Section 2.2.1. The static analytical results of the structures with different storey heights are summarized in Table 6.

Obviously, the maximum lateral displacement, storey drift angle and peak stress increase with increase of the storey height. Meanwhile, the structural ratio of height to width also increases correspondingly, which has adverse influence on the structures. On the other hand, the increase of storey height means the decrease of both the linear stiffness of columns and structural lateral stiffness. Therefore, the storey height should be as small as possible to improve the structural bearing capacity and reduce the steel consumption.

Table 6. Static Indices of the Structures with Different Storey Heights

\begin{tabular}{ccccccc}
\hline Storey height $/ \mathrm{m}$ & 1.7 & 1.8 & 1.9 & 2.0 & 2.1 & 2.2 \\
\hline Maximum lateral displacement $/ \mathrm{mm}$ & 14.9 & 16.63 & 18.52 & 20.58 & 22.81 & 25.21 \\
Maximum storey drift angle $/ \times 10^{-3} \mathrm{rad}$ & 1.18 & 1.26 & 1.34 & 1.43 & 1.52 & 1.62 \\
Peak stress $/ \mathrm{MPa}$ & 33.02 & 33.54 & 34.05 & 34.57 & 35.09 & 35.61 \\
\hline
\end{tabular}

\subsection{Influence of Linear Stiffness Ratio of Beam to Column}

Assume that the cross sections of the front/rear braces, side braces and columns are $\phi 121 \times 4$, $\phi 152 \times 5$, and $\mathrm{H}-250 \times 300 \times 8 \times 10$, respectively. Consider different cross sections of beams, and thus the linear stiffness ratios of beam to column are $1 / 89,1 / 40,1 / 20,1 / 12,1 / 7$, and $1 / 3$, respectively. The other parameters and loads are identical with those in Section 2.2.1. Various static indices of the structures with different linear stiffness ratios of beam to column are listed in Table 7 . It can be seen that, with increase of the linear stiffness ratio of beam to column, various static indices of the structure decline basically. The increase of linear stiffness ratio of beam to column is actually an improvement of constriction to columns, which effectively restricts the end rotation and displacement of columns. Additionally, the decline ratio of each static index decreases with increase of the linear stiffness ratio of beam to column. The decline rate of peak stress is even negative, that is to say, the peak stress does not decrease but increase. This indicates that excessive linear stiffness 
ratios of beam to column can cause evident stress concentration at the hoop stories, and the negative effect exceeds the positive one. Consequently, the linear stiffness ratio of beam to column should not be too large. For the model in this section, the reasonable value is $1 / 40$ to $1 / 20$.

Table 7. Static Indices of the Structures with Different Linear Stiffness Ratios of Beam to Column

\begin{tabular}{cccccccc}
\hline $\begin{array}{c}\text { Cross section of } \\
\text { beam } / \mathrm{mm}\end{array}$ & $\begin{array}{c}\text { Linear } \\
\text { stiffness } \\
\text { ratios of } \\
\text { beam to } \\
\text { column }\end{array}$ & $\begin{array}{c}\text { Maximum } \\
\text { lateral } \\
\text { displacement } \\
/ \mathrm{mm}\end{array}$ & $\begin{array}{c}\text { Decline rate } \\
\text { of maximum } \\
\text { lateral } \\
\text { displacement } \\
/ \%\end{array}$ & $\begin{array}{c}\text { Maximum } \\
\text { storey drift } \\
\text { angle } \\
/ \times 10^{-3} \text { rad }\end{array}$ & $\begin{array}{c}\text { Decline rate } \\
\text { of maximum } \\
\text { storey drift } \\
\text { angle } / \%\end{array}$ & $\begin{array}{c}\text { Peak stress } \\
/ \text { MPa }\end{array}$ & $\begin{array}{c}\text { Decline } \\
\text { rate of } \\
\text { peak } \\
\text { stress } / \%\end{array}$ \\
\hline $\mathrm{H} 100 \times 100 \times 6 \times 8$ & $1 / 89$ & $25.2(161.4)$ & 84.4 & $1.62(7.22)$ & 77.5 & $35.62(65.32)$ & 45.5 \\
$\mathrm{H} 125 \times 125 \times 6.5 \times 9$ & $1 / 40$ & $21.7(83.6)$ & 74.0 & $1.40(3.97)$ & 64.8 & $34.2(48.15)$ & 28.9 \\
$\mathrm{H} 150 \times 150 \times 7 \times 10$ & $1 / 20$ & $18.2(48.7)$ & 62.6 & $1.15(2.35)$ & 51.2 & $32.58(39.52)$ & 17.6 \\
$\mathrm{H} 175 \times 175 \times 7.5 \times 11$ & $1 / 12$ & $15.0(31.0)$ & 51.6 & $0.91(1.50)$ & 39.4 & $30.81(33.96)$ & 9.3 \\
$\mathrm{H} 200 \times 200 \times 8 \times 12$ & $1 / 7$ & $12.4(21.4)$ & 41.8 & $0.71(1.00)$ & 29.4 & $29.07(30.24)$ & 3.9 \\
$\mathrm{H} 250 \times 250 \times 9 \times 14$ & $1 / 3$ & $8.9(12.2)$ & 27.0 & $0.42(0.51)$ & 15.6 & $26.18(25.89)$ & -1.1 \\
\hline
\end{tabular}

PS: The data in brackets are the results of the corresponding conventional structures with hoop stories.

\section{PARAMETRIC ANALYSIS OF STABILITY}

The influence of various parameters such as the braces in hoop stories, linear stiffness ratio of beam to column, and the initial geometric imperfection on structural nonlinear stability is studied in this section. Similarly, the 14-storey structure with optimal arrangement of hoop stories is taken to analyze. The length, width and storey height of the structure are 8,6 , and $2.2 \mathrm{~m}$, respectively. The cross section of columns is $\mathrm{H}-250 \times 300 \times 8 \times 10$. And the load pattern is identical with that as described in Section 2.2.1.

\subsection{Influence of the Bracing Stiffness}

Let the cross sections of beams and the front/rear braces be $\mathrm{H}-150 \times 150 \times 7 \times 10$ and $\phi 121 \times 4$, respectively. And different cross sections of side braces in the hoop stories such as $\phi 73 \times 3, \phi 89 \times 4$, $\phi 102 \times 4, \phi 121 \times 4, \phi 152 \times 5, \phi 168 \times 8$, and $\phi 203 \times 9$ are considered, respectively. Then let the cross section of the side braces be $\phi 152 \times 5$, and different cross sections of the front/rear braces in the hoop stories such as $\phi 73 \times 3, \phi 102 \times 4, \phi 121 \times 4, \phi 152 \times 5, \phi 168 \times 8$, and $\phi 203 \times 9$ are considered, respectively. The relational curves of the structural ultimate load with the cross-sectional area of the side braces and that of the front/rear braces are displayed in Figures 10 and 11, respectively.

From the results as shown in Figure 10 it can be seen that, the ultimate load significantly increases with increase of the cross section of side braces at some extent, but it is not the larger the better. Combined with the results in Table 4, it can be drawn that the side braces of hoop stories have similar influence on static property and stability. There exists a rational upper limit for cross section of the side braces. For this structure, the optimal cross section of side braces is $\phi 152 \times 5$. 


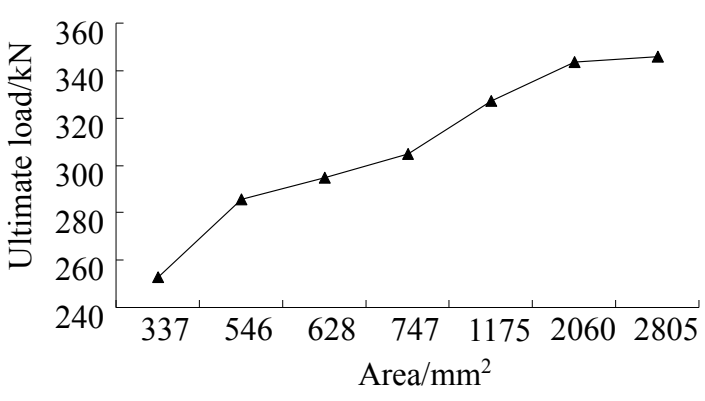

Figure 10. Relationship between

Ultimate Load and Cross-sectional Area of the Side Braces of the Structure

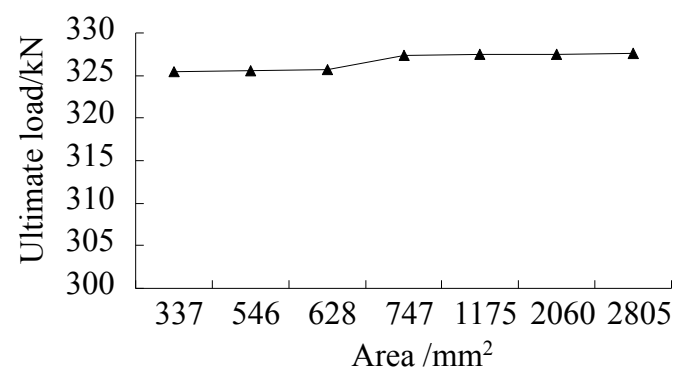

Figure 11. Relationship between Ultimate Load and Cross-sectional Area of the Front/Rear Braces of the Structure

As shown in Figure 11, the change of structural ultimate load with increase of cross section of the front/rear braces is not remarkable. Actually, from the first-order buckling mode as shown in Figure 8 , it can be understood that the structural overall stability depends on the stability of columns along the transverse direction, but the front/rear braces can only improve the structural longitudinal stability. Therefore, the change of cross section of the front/rear braces has no effect on improvement of the structural overall stability and the cross section of these members can thus be determined according to the constructional requirements.

\subsection{Influence of Linear Stiffness Ratio of Beam to Column}

It is supposed that the cross sections of the front/rear braces and side braces are $\phi 121 \times 4$ as well as $\phi 152 \times 5$, respectively. Let the cross section of columns be $\mathrm{H}-250 \times 300 \times 8 \times 10$, and by changing the cross section of beams, different values of the linear stiffness ratio of beam to column such as $1 / 89$, $1 / 40,1 / 20,1 / 12,1 / 7$, and $1 / 3$ are considered, respectively. The other conditions are identical with those in Section 4.1. The relationship curves between ultimate load and linear stiffness ratio of beam to column of the structures are displayed in Figure 12.

It can be seen that, the ultimate loads of the two kinds of models increase remarkably with increase of the linear stiffness ratio of beam to column. In essence, the increase of linear stiffness of beams will strengthen the constraint of beams to the rotation of column ends, which will shorten the interval of inflection point of columns and improve the structural stability eventually. However, the increase rate of ultimate load of model K234 in comparison with the model K000 decreases with increase of the linear stiffness ratio of beam to column as shown in Figure 13, which indicates that the hoop stories can enhance the structural stability evidently when the linear stiffness ratio of beam to column is relatively small. Synthetically, considering the effect on structural static property and stability, there exists an optimal range for linear stiffness ratio of beam to column of the structure with optimal arrangement of hoop stories, namely $1 / 40$ to $1 / 20$.

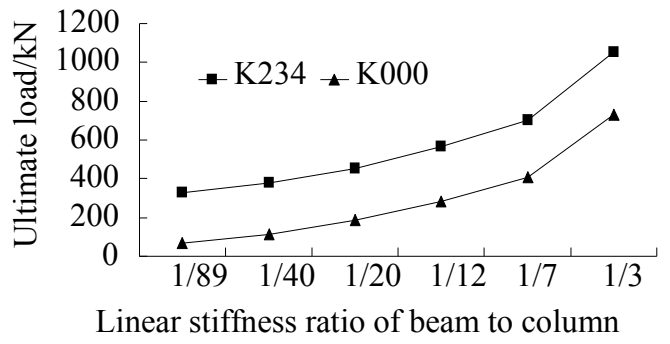

Figure 12. Relationship between Ultimate Load and Linear Stiffness Ratio of Beam to Column

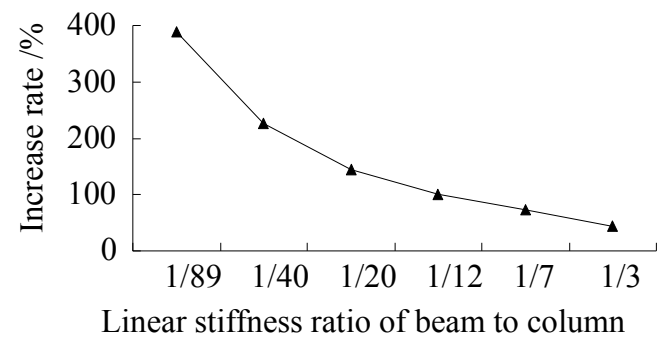

Figure 13. Relationship between Increase

Rate of Ultimate Load and Linear Stiffness Ratio of Beam to Column 


\subsection{Influence of Initial Geometric Imperfection}

The high-rise 3D parking structure with large ratio of height to width is typical tall and slender structure, which usually presents remarkable geometrical nonlinearity. It is also necessary to investigate the influence of initial geometric imperfections on structural stability. Let the cross section of the side braces be $\phi 152 \times 5$, and the other parameters are the same as those in Section 4.1. Different imperfection amplitudes such as 10, 20, 30, 60, and 100mm (about 1/3000, 1/1500, $1 / 1000,1 / 500$, and $1 / 300$ of the structural height) are considered, respectively. The load-displacement curves of the structures with different geometric imperfections are displayed in Figure 14, in which, the load is also the vertical concentrated load exerted on each column node, and the displacement is the lateral displacement of the top of the structure along the transverse direction.

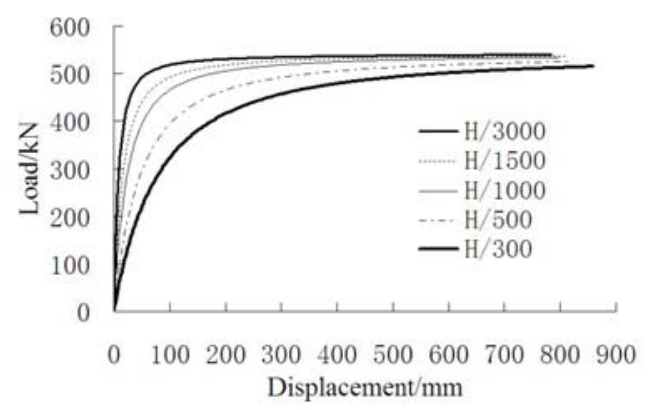

Figure 14. Load-displacement Curves of Structures with Different Geometric Imperfection Amplitudes

It can be seen that, the ultimate load decreases slightly with increase of the imperfection magnitude, but the effect is not notable. On the whole, the stability of this kind of structure is not sensitive to geometric imperfection.

\section{CONCLUSIONS}

The paper first presents a new structural arrangement style of high-rise tubular 3D parking structure, which is to set hoop stories at its proper height. Then the optimal intervals of hoop stories based on the equal stability and equal drift principle are determined. Additionally, comprehensive static property and stability of the structures with different arrangement schemes of hoop stories are compared. Finally, parameters analyses and discusses about the influence of various parameter on static properties and stability are carried out. The main conclusions can be drawn as follows.

1) The lateral stiffness of the structure with hoop stories arranged based on the equal stability and equal drift principle is obviously improved and the lateral displacement is thus controlled effectively. Moreover, the fluctuation amplitude of storey drift along the structural height is small, which benefits the stable operation of hoisting machines.

2) The axial force of columns at the bottom of the optimal structure increases for the introduction of hoop stories and the structural overturning resistance is also improved. Meanwhile, the concentration of bending moment of the columns at the lower several stories of the structure is avoided. Furthermore, the sudden change of shear force becomes not remarkable for the rational arrangement of hoop stories in the structure. 
3) The long columns are divided into several equivalent short columns due to the restraint of hoop stories to columns. The structural overall stability depends on the equivalent short columns and the stability bearing capacity is thus improved evidently. Comparison analysis shows that the ultimate load of structure with optimal arrangement of hoop stories is larger than those of the others.

4) The good structural performance verifies the rationality of arrangement of hoop stories according to the equal stability and equal drift principle, which can provide a new design idea for this kind of structure.

5) The stability and static property can be effectively improved with increase of cross section of the side braces in the hoop stories, but it is not the larger the better. Whereas, the change in cross section of the front/rear braces almost has no influence on those indices and thus the cross section of these braces can be determined according to the constructional requirements.

6) The structural lateral stiffness and overall stability can be improved with increase of the linear stiffness ratio of beam to column. However, the excessive increase will result in stress concentration of members in the hoop stories, and the effect of hoop stories becomes not notable. Therefore, the linear stiffness ratio of beam to column should not be too large.

7) On the whole, the stability of the structure with optimal arrangement of hoop stories is not very sensitive to geometric imperfection.

\section{ACKNOWLEDGMENT}

This work was financially supported by the National Natural Science Foundation of China (Grant no. 51178176), Natural Science Foundation of Hunan Province (Grant no. 13JJ6022), Doctoral Fund of Ministry of Education of China (Grant no. 20120161110019), Science and Technology Innovative Research Team Project of Universities in Hunan Province, and the Fundamental Research Funds for the Central Universities of Hunan University, which are gratefully acknowledged.

\section{REFERENCES}

[1] Amott, R., "Spatial Competition between Parking Garages and Downtown Parking Policy", Transport Policy, 2009, Vol. 13, No. 1, pp. 458-469.

[2] Amélie, Y.D. and Bryan, C.P., "The Environmental and Economic Costs of Sprawling Parking Lots in the United States", Land Use Policy, 2010, Vol. 27, No. 2, pp. 255-261.

[3] Eduardo, B., Luis, C. and João, P. F., "Parking at the UC Campus : Problems and Solutions", Cities, 2011, Vol. 28, No. 5, pp. 406-413.

[4] Yu, W.K. and Chung, K.F., "Axial Buckling of Bamboo Columns in Bamboo Scaffolds", Engineering Structures, 2005, Vol. 27, No. 1, pp. 61-73.

[5] Tommy, Y. L. and Cui, H.Z., "Strength Analysis of Bamboo by Microscopic Investigation of Bamboo Fibre", Construction and Building Materials, 2008, Vol. 22, No. 7, pp. 1532-1535.

[6] Khosrow, G., "Bamboo as Reinforcement in Structural Concrete Elements", Cement and Concrete Composites, 2005, Vol. 27, No. 6, pp. 637-649.

[7] Ma, J.F., Chen, W.Y. and Zhao, L., "Elastic Buckling of Bionic Cylindrical Shells Based on Bamboo" Journal of Bionic Engineering, 2008, Vol. 7, No. 2, pp. 231-238. 
[8] Karthikeyan, C., Krishnan, R. and Princy, S.A., "Bionics and Structural Biology: a Novel Approach for Bio-energy Production", Journal of Bionic Engineering, 2008, Vol. 5, No. 1, pp. 25-32.

[9] Zhao, L., Ma, J.F. and Wang, T., "Lightweight Design of Mechanical Structures Based on Structural Bionic Methodology”, Journal of Bionic Engineering, 2010, Vol. 7, No. Suppl., pp. 224-231.

[10] He, Y.J. and Zhou X.H., “Approximate Analytical Method of Multi-storey or High-rise Steel Three-dimensional Parking Structures", International Journal of Advanced Steel Construction, 2012, Vol. 8, No. 2, pp. 112-123.

[11] Li, G.Q., "Design of High-rise Steel Structure", 2004, Beijing, China Building Industry Press (In Chinese).

[12] Hyo, G.K. and Jong, Y.S., "Live Load Factors for Parking Garage Members", Structural Safety, 2000, Vol. 22, No. 3, pp. 251-279.

[13] Salemi, F., Salone, V. and Wang, W.D., "Stability of a Competition Model with Two-stage Structure", Applied Mathematics and Computation, 1999, Vol. 99, No. 2, pp. 221-231.

[14] Zhao, Y.C., Xian, C. and Dong, S.L., "Strength and Stability Analysis of Circular Steel Arches in a Long-span Ellipsoidal Shell Structure", China Civil Engineering Journal, 2005, Vol. 38, No. 5, pp. 15-23 (In Chinese).

[15] Widjaja, BR., "Path-following Technique Based on Residual Energy Suppression for Nonlinear Finite Element Analysis”, Computer \& Structures, 1998, Vol. 66, No. 2, pp. 201-9. 